\title{
International Integration with Heterogeneous Immigration Policies
}

\author{
Nicola D. Coniglio ${ }^{(1)}$ and Kenji Kondoh ${ }^{(2)}$ \\ ${ }^{(1)}$ University of Bari “Aldo Moro”, Italy and NHH Norwegian School of Economics (email \\ address: Nicola.Coniglio@nhh.no) \\ ${ }^{(2)}$ Chuckyo University, Nagoya - Japan (email address: kkondo@mecl.chuckyo-u.ac.jp)
}

This version: 18 September 2013 - Do not cite without author's permission

\begin{abstract}
This paper investigates the welfare effects of developed countries with heterogeneous and uncoordinated immigration policies. We build a simple three country model where two rich countries with different immigration policies receive immigrants from the third developing country. We consider the effects of economic integration in the form of free mobility of native workers and show that under certain conditions, wage gap between two develop countries is crucial whether integration ends in win-win or lose-lose.
\end{abstract}

JEL Code: F02, F22

Keywords: immigration policy; economic integration; policy externality; international migration 


\section{Introduction}

Migration flows are a powerful source of economic and social change in both destination and origin countries. The regulation of the flows of migrants (incoming and outgoing) is a very sensitive policy area which is mainly in the hands of domestic policymakers with almost no room left for multilateral policymaking. Also in areas of the world were the process of economic and social integration between countries is pervasive and intense such as the European Union, the harmonization of immigration policies is confined to the establishment of uniform rules on specific issues (such as asylum seekers regulations ${ }^{1}$ ) or the definition of broad principles.

Autonomous immigration policies in an interdependent economic area might represent a source of concern if they generate distortions and policy externalities. Within the EU, the need to set common rules has long been acknowledged; in fact at the Tampere European Council in October 1999, policy objectives and main components of a common immigration policy were defined. After almost a decade - in October 2008 a European Pact on Immigration and Asylum was adopted at the European Council but member countries still retain a very high degree of freedom in defining their immigration policies. The only focal point for national immigration policies - within the EU and in general for most OECD countries - is a generalized trend of more restrictive rules which aims at limiting the number of immigrants from third countries. Within the EU, national policies greatly differ in many respects; who, how many, for how long and under which conditions and regulations third-countries individuals might cross the border and legally reside and work. Some countries like the UK (since October 2008), Denmark (since July 2008), the Netherlands (January 2009) and Austria (effective from July 2011) ${ }^{2}$ have recently introduced a point-based system aimed at selecting the "quality" of migrants at entry. Other countries have introduced some rules which simplify labour migration for some specific highly skilled individuals like students in Germany or executives and management professionals in Belgium.

A minimum requirement on language abilities is often imposed by some destination countries with the aim of selecting those immigrants which have a higher probability of being fully economically and socially integrated. ${ }^{3}$

\footnotetext{
1 The recent large increase in migration flows from the North-African coast toward Italy as a consequence of the wave of political unrest in the sending area shows the difficulties within the European Union in enforcing common rules and coordination in the management of external borders.

2 The Austrian point base system will replace the former immigration quota system and will be effective from July 2011. These policies are aimed at attracting highly skilled individuals and employees in shortage occupations.

${ }^{3}$ In Austria for instance, the National Integration Plan introduced in 2009 established that a basic knowledge of German language prior to arrival is required for low-educated family migrants. A similar regulation was adopted by
} 
A quota system for labour migrants is the main gate to immigration in countries like Italy, Spain, Greece, Portugal, France. ${ }^{4}$ On the contrary the Swedish system is entirely demand driven (since the end of 2008); the size of the flows reflects the needs of the labour market and skill requirements are defined only by employers. EU countries substantially differ also with respect to the degree of irregularity of migration flows; the phenomenon is in fact quite large in some countries such as Italy, Greece, France and Spain while relatively limited in many other EU countries.

The policy differences outlined above demonstrate that sovereignty over immigration policies has not changed substantially notwithstanding the deeper economic integration between EU countries and, in general, between the club of rich countries.

In this paper we present a simple theoretical framework which allows us to analyse the interdependence of autonomous and exogenously determined immigration policies in a context of integration of labour markets due to deeper economic integration between countries. We consider a three country model where individuals form a large developing country might migrate in a federation of state composed by two developed countries with autonomous immigration policy. We consider the case of heterogeneous policies where one destination country adopts selective immigration regulation in the form of minimum skills requirements and the other uses a quota system. The aim is to investigate the effects of autonomous change in immigration regulation (policy externalities) in the federation and the welfare consequences of free mobility of natives when immigration policies are heterogeneous and uncoordinated.

Our results show that a more restrictive immigration policy in the sense of increasing the skills level required for legal entry may lead to negative welfare effects in another developed country while a more restrictive policy to illegal workers in the sense of higher penalty cost will lead positive welfare effects. In addition we show that economic integration between the two destination countries in the form of free mobility of native workers (like in the EU) might lead to interesting welfare effects: under certain conditions about the population of developed country with quantitative restriction policy and about the effects of selective immigration policies of another developed country with qualitative restriction policies, whether economic integration will end in

France in 2008: as a condition for family reunification a French language and culture test has to be passed while applicants are still in the country of origin. The "language test" is in some cases required in order to obtain long term residence permit (like in Italy and Denmark). The UK Government has recently passed a new regulation which imposes an English language test also for partners of migrants. In point-based systems, language abilities are either compulsory (UK, Australia, New Zealand) or are given a large weight in the assessment process (Denmark, Netherland, Canada).

${ }^{4}$ Numerical limits to immigration, equivalent to explicit quotas, might be imposed also indirectly by modifying acceptance procedures. 
win-win result or lose-lose result depends on the wage difference between two countries before integration.

This paper is related to Djajic (1989), a pioneering study about the effect of qualitative restrictions on international migration. As in our framework, skills are considered as the experience accumulated in school and at work as well as in everyday life, which increases the productivity of an individual. To obtain permission to enter the host country, potential immigrants are required to have a minimum number of skills; thus, there is an inverse relationship between a worker's ability to acquire skills and the age at which he might become a qualified migrant. Kondoh (2000) extended Djajic (1989) by considering the alternatives of labour mobility - illegal migration. Our study extends these studies by considering a three-country framework were only one of the two potential destinations adopts qualitative entry restrictions while the other country sets an optimal immigration quota. The paper is also related to McDougal (1960) and Ramaswami (1969) - and several subsequent theoretical studies - who investigate the effects of introducing foreign workers for economic welfare or national income of the host country; these studies emphasize that optimally controlled immigration (by means of a immigration tax, and hence an setting indirectly an immigration quota) is welfare enhancing with respect to free international immigration ${ }^{5}$.

In a related study, Brucker and Schroder (2010) show the existence of cross-country spill-over effects of selective immigration policy. Using data on a panel of OECD countries between 1980 and 2005, the authors find evidence of a contagion effects of selective immigration policy; neighbouring countries are induced to introduce selective immigration.

Although related, the aim of this paper is different since we focus on welfare effects of autonomous policy change and on the nexus between free internal mobility due to economic integration and asymmetric immigration policies.

Also the paper by Bertoli et al (2009) consider a three country model where strategic interactions arise in the setting of immigration quota. The authors show the inefficient outcome of uncoordinated immigration policy setting due to the fact that a country considers the negative externality imposed on the other country in terms of a reduced level of human capital embedded in the flows. Jesus Fernandez-Huertas Moraga (2008) considers another kind of policy externalities, ie between origin and

\footnotetext{
5 There exist a series of papers devoted to explaining the asymmetric nature of proposition - a relatively capital abundant country sharing a common technology with a low-wage foreign country gains more by hiring foreign workers to produce at home than it does by sending its capital abroad to earn the relatively high return found there. See Webb (1970), Bhagwati (1979), Calvo and Wellisz (1983), Bhagwati and Srinivasan (1983), Ruffin (1984), Jones and Coelho (1985), Jones, Coelho and Easton (1986), Kuhn and Wooton (1987), and Jones and Easton (1989).
} 
destination countries in a theoretical model where bilateral immigration agreements emerge as a way to internalize such externalities.

The paper is organized as follows. In Section 2, we present a simple three-country model of migration from a poor origin country toward a rich area composed by two countries with different immigration policy. In Section 3 we present and discuss the effects of (autonomous and uncoordinated) economic integration between the two destination countries. Concluding remarks are in Section 4.

\section{A Simple 3-Country Model of International Migration}

Let consider a stylized world economy composed by three large countries: two identical rich countries $A$ and $B$ and a large developing country $C$. Each country produces the same good by using labour and capital under perfect competition. The price of the good is the numeraire. We assume that the three countries are endowed with a fixed amount of capital $\left(K_{A}, K_{B}\right.$ and $K_{C}$ ), and at every instant, a constant number of individuals, $N_{j}$ is born in each country $j=A, B, C$ and lives for a lifespan equal to $T$. In the absence of migration, the total number of workers in country $j$ can be expressed as $L_{j}=T N_{j}$.

The output in each country is produced with the aid of capital and labor. Let us specify the production function in a country $j$ by $X_{j}=K_{j} L_{j}-\frac{a}{2} L_{j}^{2}-\frac{b}{2} K_{j}^{2}$ where we assume the following conditions are satisfied before and after international migration, $a<\frac{K_{j}}{L_{j}}$ and $b<\frac{L_{j}}{K_{j}}$. We now have the following properties under the perfect competition in both factor markets, $\partial X_{j} / \partial K_{j}=L_{j}-b K_{j}=r_{j}>0, \quad \partial X_{j} / \partial L_{j}=K_{j}-a L_{j}=w_{j}>0, \quad \partial^{2} X_{j} / \partial K_{j}^{2}=-b<0$, $\partial^{2} X_{j} / \partial L_{j}^{2}=-a<0$, and $\partial^{2} X_{j} / \partial L_{j} \partial K_{j}=1>0$, where $r_{j}$ and $w_{j}$ denote, respectively, the rental price of capital and the wage rate in country $j$. To sharpen the focus of our analysis on the problem of international migration, we assume that capital is equally endowed to each country (i.e. $K_{A}=K_{B}=K_{C} \equiv K$ ) and it is country specific and immobile between countries like land. Countries differ in their labour endowments; the 
new-born labour in each period and the aggregate stock of labour in country $A$ and $B$ are the same and those are, respectively, smaller than those of country $C$. Wage rates in the three countries will reflect those relations, $w_{A}^{0}=w_{B}^{0}>w_{C}^{0}$ where $w_{j}^{0}$ denotes the autarkic wage rate in country $j$. The wage gap implies that the two developed countries confront, at least potentially, an inflow of workers from country C. Following Djajic (1989), to simplify our analysis, the dynamic problems involving capital accumulation and population growth are not addressed in the paper. We assume that receiving countries have two different immigration policies in order to control the flood of immigrants: One policy is a qualitative immigration policy. The receiving country chooses the minimum level of skills with which immigrants are allowed to migrate legally. Another policy is a quota system. The receiving country chooses the optimal level of tax imposed on the income of immigrants to control the total amount of foreign workers.

In what follow we describe the alternative emigration strategies for individuals from the origin country $C$.

\subsection{Welfare Function of the receiving country}

Firstly, let us the benchmark cases of receiving countries which introduce foreign workers alone. In order to capture the stylized facts reported above, we consider the welfare function of the receiving countries as the sum of national income including tax revenue and negative externalities caused by low skill immigrants,

$$
W_{j}=r_{j} K+w_{j} L_{j}+T_{j}-h_{j}\left(Q_{j}\right)
$$

where $T_{j}$ denotes the tax income, $Q_{j}$ denotes the average quality of immigrants of country $j$, respectively. We consider negative externality of low quality immigration which reduces domestic economic welfare, $h_{j}$, and we assume $h_{j}^{\prime}<0$ and $h_{j}^{\prime \prime}>0$ without loss of generality. We now introduce the only difference between two developed countries. Compared with Country $B$, Country $A$ is much more sensitive in this externality which implies $h_{A}(Q)>h_{B}(Q)$ for all $Q$. 
In case of qualitative immigration policy, the government of the receiving country only adopts the optimal level of skill requirement. Therefore there is no tax income and increased immigration causes positive effects on national income (the first and second term of RHS of (1) but negative effects on negative externality (the last term of RHS of (1)) because expanded immigration implies permission of relatively lower quality workers' legal immigration.

On the other hand, if the receiving country adopts quota, it is possible to optimally control the number of immigrants by imposing tax on the income of immigrants. Therefore in this case, $T_{j}>0$. The average quality of immigrants is, on the other hand, keeps constant because it does not depend on the number of immigrants.

\subsection{Skills formation and legal migration to the country with selective immigration policy}

Let us consider the first benchmark case of immigration policy, qualitative selection policy. Due to the existence of a wage gap, if permitted, workers will migrate from Country $C$ to Countries $A, B$ up to a point where wages are equalized. Let assume that a minimum entry skill requirement, $\bar{Q}$, is imposed by the government of country $A$, for instance in the form of destination-specific human capital such as language proficiency. For simplicity, let assume that this human capital is valuable only in country $A$ and can be acquired by potential migrants at a cost equal to $\mu{ }^{6}$

In a similar fashion as in Djajic (1989), we assume that each new-born individual in country $C$ differs from the others in his capacity to develop productive skills. Although the cost of acquiring the destination-specific human capital is constant and equal to $\mu$, learning time depends on inborn individual abilities and the brightest individuals are able to acquire the minimum required level of skills $\bar{Q}$ for migrating legally in Country $A$ in less time than others. We assume that each generation is an exact replica of the previous one such that the distribution of skill formation within the population is constant over time. As $N_{C}$ is considered to be sufficiently large, we may treat every age group as a continuum of individuals with different abilities. Now, let us index each individual by $i \in[0,1]$. Individual abilities are inborn and can be measured

\footnotetext{
${ }^{6}$ In the current framework of the model we restrict the analysis to a case were the required destination-specific human capital is acquired only before (legal) migration; we abstract for simplicity and without loss of generality from the possibility of an improvement in individuals' abilities during the (illegal or legal) migration spell in the destination country.
} 
by a continuous function, $p(i)$, where $p^{\prime}(i)>0$. The accumulation of skills by individual $i$ at age $t(0 \leq t \leq T)$ is assumed to be given by:

$$
Q(i, t)=p(i) q(t)
$$

where $q(0)=1, q^{\prime}(t)>0, q^{\prime \prime}(t)<0$, and $T$ denotes the retirement age. Individual with a higher potential ability can acquire the necessary skills for meeting the selective criteria imposed by Country $A$ faster and hence migrate at a younger age (in other words, they can enjoy a longer migration spell).

Once individuals from Country $C$ have accumulated the required level of skills , they do not postpone their departure for Country $A$. We then obtain the following relationship between $\bar{Q}, i$ and the migration age $\tau$ :

$$
\tau=\Psi(i, \bar{Q})
$$

where $\Psi_{1}<0, \Psi_{2}>0$ and $\tau$ decreasing in $i$ and increasing in $\bar{Q}$. The function $\Psi(i, \bar{Q})$ is given by $q^{-1}[s(i) / \bar{Q}]$. This relationship is depicted by the $\bar{Q} \bar{Q}$ schedule in Figure 1.

The wage rate of a worker in country $C, w_{C}$ is low and for simplicity let assume that income is entirely spent on consumption and not saved for sustaining future consumption; in other word the desired minimum level of consumption is by assumption lower or equal to $w_{C}$. In case of successful legal migration in country $A$, the income of an immigrant in every period is equal to the wage rate $w_{A}^{M}\left(>w_{C}^{M}\right)$, where $w_{j}^{M}$ denotes the wage rate of country $j$ after migration. Individuals in Country $C$ whose potential abilities are quite low would accumulate the required level of skills $\bar{Q}$ only at a late age $\tau$, in turn this implies a reduced potential migration spell. For individuals below a critical threshold of abilities the expected returns from migration will fail to compensate for the cost of the destination-specific human capital $\mu$. In other 
words, an individual who has a potential ability lower than $\underline{i}$ (the marginal legal migrant) in the following equation will have no incentive to invest in human capital in order to match the requirement imposed by the selective immigration scheme of Country A:

$$
\left(w_{A}^{M}-w_{C}^{M}\right)[T-\tau(\underline{i}, \bar{Q})]-\mu=0
$$

where for simplicity we assume no inter-temporal discount factor. For a given $\bar{Q}$ established by the government of Country $A$, the total amount of legal migrants is represented by the area $L_{1}$ in Figure 1 .

(Figure 1 is around here)

\subsection{Illegal migration in the country with selective immigration policy}

Obtaining a legal working visa in country $A$ is the preferred choice for migrants but this opportunity is regulated by minimum entry requirement in terms of skills $\bar{Q}$ (which in turn defines the size of eligible individuals within the origin country population). As there remains the wage gap between country $A$ and $C$, an individual in Country $C$ who is not able to migrate through the "main door" (i.e. through the selective screening), still has a positive chance of migrating illegally through the "windows" in Country $A$ or migrate to the another rich Country $B$ (see next paragraph). We assume that individuals are risk-neutral when they decide to migrate illegally. Illegal immigrants are assumed to well disguise as legal immigrants at the border control and the government of $A$ adopts a policy effort in trying to reduce illegal residency via internal enforcement of immigration. This means that, if detected while trying to enter the country or while working, an illegal worker is fired and deported. Let $\rho \in[0,1]$ denote the probability of detection in every period which will depend on policy efforts and on structural characteristics of the country which enhance or reduce the ability to enforce the law (for instance the permeability of borders or the existence of job opportunities for illegal workers in the black economy). The probability of detection is known to potential illegal migrants and is a positively related function of total amount of illegal immigrants, $L_{2}$; in other words as the government efforts to reduce illegal migration increases drastically constant and therefore the probability of detection for an illegal worker is an increasing function of the total amount of illegal workers. Moreover we 
assume the change in probability of detection is sufficiently small compared with effects on wage rates caused by illegal immigration. Let the additional necessary cost of disguise which illegal migrant should pay to pretend to be a legal migrant, $\theta$, be constant. In steady state, in each period, the expected income of illegal migrants would be equal with that of those left behind:

$$
\tilde{w}_{A}^{M} \equiv\left(1-\rho\left(L_{2}\right)\right) w_{A}^{M}+\rho\left(L_{2}\right) w_{C}^{M}-\theta=w_{C}^{M}
$$

where we assume for simplicity that the trip cost of migration (and return) is null.

Country $A$ can control the required skill level $\bar{Q}$ to maximize economic welfare, $W_{A}$. Two opposite economic effects are assumed caused by an increase in the minimum level of required skills (for instance the requirement of higher language proficiency). There exists a positive effect which results from lower negative externality on the welfare caused by increased average quality of workers. On the other hand, there exists a negative effect on the economy because of reduced production by smaller labour input. Note that in this simple one-good model with two factor à la MacDougal (1960), a decrease in labour will cause negative effect on the economic welfare of native inhabitants of Country $A, W_{A}$.

As $L_{2}$ is the function of the wage gap between two countries, $A$ and $C$, and those wages are directly determined by the number of legal immigration, $L_{1}$, and therefore the minimum skill requirement, $\bar{Q}$. Now we can specialise $W_{A}$ as a function of $\bar{Q}$;

$$
\begin{aligned}
W_{A} & =r_{A}^{M}\left(L_{1}, L_{2}\right) K+w_{A}^{M}\left(L_{1}, L_{2}\right) L_{A}-h\left(Q_{A}\left(L_{1}, L_{2}\right)\right) \\
& =K\left(L_{A}+L_{1}+L_{2}\right)-\frac{a}{2}\left(L_{A}+L_{1}+L_{2}\right)^{2}-\frac{b}{2} K^{2}-h\left(Q_{A}\left(L_{1}, L_{2}\right)\right) \\
& \equiv W_{A}(\bar{Q})
\end{aligned}
$$


where $L_{1}=L_{1}(\bar{Q}), \quad L_{2}=L_{2}\left(L_{1}(\bar{Q})\right), \quad \partial L_{1} / \partial \bar{Q}<0^{7}, \quad \partial L_{2} / \partial L_{1}<0^{8}, \quad \partial Q_{A} / \partial L_{1}>0$ and $\partial Q_{A} / \partial L_{2}<0$. The effect on negative externality $h$ caused by an increase in $\bar{Q}$ is surely negative which implies that the decreasing average quality by decreasing legal migrants and increasing illegal migrants should reduce economic welfare. On the other hand, the effects on National Income of Country $A$ might be positive or negative depending on the magnitude of two opposite effects. An increase in $\bar{Q}$, minimum skill requirement, causes negative effect on the number of legal migrants but positive effect on that of illegal migrants. From (5), we have

$$
-1>\left.\frac{d L_{2}}{d L_{1}}\right|_{d L_{j}=0}=-\frac{\Omega}{\Omega+\rho^{\prime}\left(w_{A}^{M}-w_{C}^{M}\right)}
$$

where $\Omega \equiv \partial\left(w_{A}^{M}-w_{C}^{M}\right) / \partial L_{M}<0$ and applying (7) we can assert that the latter effect dominates and An increase in minimum skill requirement enhance National Income of Country A. Thus there exists so called "boomerang effect" in our model. From (6), we have

$$
\left.\frac{\partial W_{A}}{\partial \bar{Q}}=\frac{\partial L_{1}}{\partial \bar{Q}}\left\{\left(1+\frac{\partial L_{2}}{\partial L_{1}}\right)\right]\left[K-a\left(L_{A}+L_{1}+L_{2}\right)\right]-\frac{\partial h_{A}}{\partial Q_{A}}\left(\frac{\partial Q_{A}}{\partial L_{1}}+\frac{\partial Q_{A}}{\partial L_{2}} \frac{\partial L_{2}}{\partial L_{1}}\right)\right\}
$$

where the second term in curly braces, $-\frac{\partial h_{A}}{\partial Q_{A}} \frac{d Q_{A}}{d L_{1}}=-\frac{\partial h_{A}}{\partial Q_{A}}\left(\frac{\partial Q_{A}}{\partial L_{1}}+\frac{\partial Q_{A}}{\partial L_{2}} \frac{\partial L_{2}}{\partial L_{1}}\right)$ is positive in sign and from (7), the first term is negative. Remembering the assumption that $h_{j}^{\prime}<0$ and $h_{j}^{\prime \prime}>0$, we can assert there exist optimal level of minimum skill requirement $\bar{Q}^{*}$ which satisfies that $W_{A}^{\prime}\left(\bar{Q}^{*}\right)=0$ and below (8) under the

7 An increase in $\bar{Q}$ enhances the migration age $\tau$ from (3). From (4) it follows to expand the wage gap between $w_{A}^{M}$ and $w_{C}^{M}$, and thus reduces $L_{1}$ from (4).

${ }^{8}$ An increase in $L_{1}$ reduces the wage gap between $w_{A}^{M}$ and $w_{C}^{M}$, which straightforwardly implies increasing $1-\rho\left(L_{2}\right)$ and decreasing $L_{2}$ from (5). 
assumption that $h_{j}^{\prime \prime}>0$ is sufficiently large.

$$
w_{A}^{M}\left(1+\frac{\partial L_{2}}{\partial L_{1}}\right)-\left[\frac{\partial h_{A}}{\partial Q_{A}} \frac{d Q_{A}}{d L_{1}}\right]=0
$$

\subsection{Migration in the country with immigration quota}

We now consider another benchmark case that immigration quota is optimally controlled by the government of Country $B$ alone. Let consider a situation where the immigration quota is endogenously determined by the government of Country $B$ in a welfare maximization process. ${ }^{9}$ Country $B$ can optimally introduce a tax - which might be considered as the cost of a working visa - on the income of foreign workers in order to maximize economic welfare of natives, namely the national income of this country. Let us assume that this tax will be imposed at the beginning of the migration spell, entry tax and it is impossible to migrate Country $B$ without paying this tax. In equilibrium, the following equation must hold:

$$
T\left(w_{B}^{M}-w_{C}^{M}\right)=v
$$

where $v$ is the tax rate or the price of a working visa. Equation (6) implies that wage difference between two countries in each period should be equal to $v / T$ in equilibrium It is noteworthy that different from qualitative restriction, as the expected wage between two countries, $w_{B}^{M}-(v / T)$ and $w_{C}^{M}$ are the same, illegal migration from $C$ to $B$ will not occur in case of strict immigration policy of Country $B$. Wages are set in competitive markets and marginal products of labour of Country $B$ and $C$ are a decreasing function of the stock of labour in equilibrium as shown in Figure 2. The BB' (CC') line shows the relationship between labour inputs and marginal products of labour in Country $B$ (Country $C$ ). In the figure $O O^{*}$ is equal to the sum of labour endowment of both Country $B$ and $C$. Without loss of generality, we assume $L_{B}<L_{C}$ and that the

\footnotetext{
${ }^{9}$ We model a situation where the government of Country $B$ has a more pro-immigration stance with respect to Country $A$ and extracts rents from immigrants (selling entry visa) in order to maximize the welfare of natives.
} 
optimal immigration quota defined by Country $C$ is denoted by $L_{3}$ as expressed in Figure $2^{10}$

(Figure 2 should be around here)

The optimal choice by the government of Country $B, v^{*}$, should satisfy the following condition to maximize the area $S$ of Figure 2:

$$
v^{*}=\frac{1}{3} a T\left(L_{C}-L_{B}\right)
$$

Moreover, the number of immigrants from country $C$ to $B$, i.e. the immigration quota $L_{3}$, and economic welfare of Country $B, W_{B}$, which is equal to the sum of national income and negative externality of immigrants, can be written respectively as:

$$
\begin{aligned}
& L_{3}=\frac{1}{3}\left(L_{C}-L_{B}\right) \\
& W_{B}=r_{B} K+w_{B} L_{B}+T-h\left(Q_{B}\right)=-\frac{a}{2} L_{B}^{2}+\left(K-\frac{a}{6}\right) L_{B}+\frac{a}{6} L_{C}-h\left(Q_{B}\right)
\end{aligned}
$$

Without any other labour outflow from Country $C$, the Average quality of foreign workers, $Q_{B}$, is constant regardless of the number of immigrants, $L_{3}$, and that equal to $1 / 2$ because all of individuals in Country $C, i \in[0,1]$, intend to migrate and who will be able to obtain entry visa depends only random probability.

\subsection{Interaction of immigration policies and optimal choice}

Now let us proceed to the Nash equilibrium of immigration policies between two developed countries. Firstly, consider the optimal policy of Country $B$ when Country A should be supposed to adopt qualitative restriction policy. The higher ability holders surely migrate to the country with qualitative restriction policy because they

\footnotetext{
${ }^{10}$ The immigration quota is indirectly set by the government using an (equivalent) entry visa. It is widely known that in the fashion of McDougal model, compared with autarky, free factor mobility benefits both the host and the source countries in national income or welfare. But focusing only on the national income or welfare of the host country, optimal level tax on the income of immigrants could be welfare improving and better than free immigration case.
} 
will be paid $w_{A}^{M}$ after migration which is higher than the following wage rates, the expected wage rate for illegal migrants to $A, \tilde{w}_{A}^{M}$, the wage rate after tax paid by country $B$ (if adopted quota), $w_{B}^{M}-v / T$, and the wage rate of those left behind in Country $C, w_{C}^{M}$. Therefore if Country $B$ adopts quota, individuals $i \in[\underline{i}, 1]$ will migrate Country $A$ and the average quality of immigrants to country $B$ is now $\underline{i} / 2$, which is less than the benchmark case without qualitative restriction policies by another developing country. Moreover because of the outflow of workers from Country $C$ to $A$, the population gap between Country $B$ and $C$ is also smaller. These two effects cause negative effects on $W_{B}$. On the other hand, if Country $B$ also adopts qualitative restriction policies, as there is no difference between two developed countries, legal workers should be equally shared by half and half. Now because of less legal high quality immigrants, the optimal level of minimum skill requirement of both countries will fall down and which also cause negative effects on the economic welfare. We now can assume that even the average quality of immigrants in case of quota is lower, economic welfare could be higher because of positive tax income. Thus Country $B$, which is less sensitive in the quality of immigrants, select quota.

Next let us consider the optimal policy of Country $A$ when Country $B$ should be supposed to adopt quota. Adopting qualitative restriction policy, Country $A$ can introduce all of higher quality immigrants. On the other hand, if Country $A$ also adopts quota, the average quality of immigrants is $1 / 2$. Remembering that Country $A$ is more sensitive in the quality of immigrants, qualitative restriction policy should be preferred. Or we can also assume that the population gap between the receiving countries and Country $C$ is not large enough by which tax income dominates qualitative gain by introducing good workers alone.

Under above situation, both policy choices (Quota, Quota) and (Qualitative, Qualitative) are not realized in equilibrium. Depending on their preferences, we can assume that Country $A$ adopts qualitative restriction policy while Country $B$ adopts quota in equilibrium ${ }^{11}$.

11 As there is no difference between two developed countries and in the benchmark case, 
Now because of the existence of Country $A$, the optimally controlled tax, immigrants and welfare of Country $B$ should be rewritten as:

$$
\begin{aligned}
& v^{*}=\frac{1}{3} a T\left(\tilde{L}_{C}-L_{B}\right), \\
& L_{3}=\frac{1}{3}\left(\tilde{L}_{C}-L_{B}\right), \\
& W_{B}=-\frac{a}{2} L_{B}^{2}+\left(K-\frac{a}{6}\right) L_{B}+\frac{a}{6} \tilde{L}_{C}-h\left(\tilde{Q}_{B}\right),
\end{aligned}
$$

where $\tilde{L}_{C}=L_{C}-L_{1}-L_{2}$ and $\tilde{Q}_{B}=\underline{i} / 2$.

We now have the following system:

$$
\begin{aligned}
& \left(1-\rho\left(L_{2}\right)\right)\left(w_{A}^{M}-w_{C}^{M}\right)=\theta, \\
& a\left(L_{1}+L_{2}\right)\left(1+\frac{\partial L_{2}}{\partial L_{1}}\right)-\left[\frac{\partial h_{A}}{\partial Q_{A}} \frac{d Q_{A}}{d L_{1}}\right]=0,
\end{aligned}
$$

where the wage rates of Country $A$ and $C$ are endogenously determined and depend upon the distribution of the population between the three countries:

$$
\begin{aligned}
& w_{A}^{M}=K-a\left(L_{A}+L_{1}+L_{2}\right), \\
& w_{C}^{M}=K-a\left(L_{C}-L_{1}-L_{2}-L_{3}\right)=K-a\left(\frac{2}{3} L_{C}-\frac{2}{3} L_{1}-\frac{2}{3} L_{2}+\frac{1}{3} L_{B}\right),
\end{aligned}
$$

Substituting (13) and (14) into (5'), we have two equations with two endogenous

quota might or might not be better than qualitative restriction depending on parameters. What we considered here is that if one country is the leader who can choose one of the better policies, the other country surely will strategically choose different immigration policy. 
variables, $L_{1}$ and $L_{2}{ }^{12}$. The system above will determine the immigration outflows from Country $C$ to Country $A$ and under given parameters $L_{A}, L_{B}, L_{C}, \mu$ and $\theta$, optimal skill requirement $\bar{Q}$ is determined by

$$
L_{1}=L_{1}\left(\bar{Q}, \mu, w_{A}^{M}, w_{C}^{M}\right),
$$

and wage rate of Country $\mathrm{B}, w_{B}^{M}$ is determined by

$$
w_{B}^{M}=K-a\left(L_{B}+L_{3}\right)=K-a\left(\frac{4}{3} L_{B}-\frac{1}{3} L_{C}+\frac{1}{3} L_{1}+\frac{1}{3} L_{2}\right) .
$$

These complete the model.

\section{Economic integration and free mobility of native workers}

Now let us consider the case of economic integration between two developed countries with heterogeneous immigration policies. In the current EU framework, workers who are legal permanent residents of a member State are free to move across boundaries. In this section we model international integration between Country $A$ and $B$ as a removal of barriers to free mobility of native workers within the common economic area. According to the differences in labour endowment after immigration from Country $\mathrm{C}$ in the two countries, two possible scenarios arise in our model:

Case 1: $L_{A}+L_{1}+L_{2}<L_{B}+L_{3}$,

Case 2: $L_{A}+L_{1}+L_{2}>L_{B}+L_{3}$.

12 Now (7) can also be rewritten in $-1<\frac{\partial L_{2}}{\partial L_{1}}=-\frac{\frac{a}{3}(1-\rho)}{\frac{a}{3}(1-\rho)+\rho^{\prime}\left(w_{A}^{M}-w_{C}^{M}\right)}<0$. 
Remembering that $K_{A}=K_{B}$, in case 1 , as we can conclude $w_{A}^{M}>w_{B}^{M}$ in equilibrium, international migration from Country $B$ to $A$ occurs if permitted. In Case 2 , on the other hand, because of $w_{A}^{M}<w_{B}^{M}$, domestic workers of Country $A$ start to migrate to $B$.

Let start to consider the effects of a change in Country $A$ and Country $B$ populations on immigration from the third developing Country $C$. Applying (5') and (7), we obtain the following equation about the economic welfare of Country $A$ (see Appendix for detail calculation and sign of $\frac{d\left(L_{1}+L_{2}\right)}{d L_{A}}-\frac{d\left(L_{1}+L_{2}\right)}{d L_{B}}$ :

$$
\begin{aligned}
\frac{d W_{A}}{d L_{A}} & -\frac{d W_{A}}{d L_{B}}=\frac{\partial W_{A}}{\partial L_{A}}+\frac{\partial W_{A}}{\partial\left(L_{1}+L_{2}\right)}\left[\frac{d\left(L_{1}+L_{2}\right)}{d L_{A}}-\frac{d\left(L_{1}+L_{2}\right)}{d L_{B}}\right] \\
& =\frac{\partial W_{A}}{\partial L}\left\{1+\left[\frac{d\left(L_{1}+L_{2}\right)}{d L_{A}}-\frac{d\left(L_{1}+L_{2}\right)}{d L_{B}}\right]\right\}>0
\end{aligned}
$$

As the sign of (16) should be positive under the assumption in Appendix, we can conclude that in case 1 (2), international migration of domestic workers from Country $B$ to $A$ ( $A$ to $B$ ) will improve (reduce) economic welfare of Country $A$.

Concerning with the welfare of Country $B$, from (12), we have

$$
\begin{aligned}
& \frac{d W_{B}}{d L_{B}}=-a L_{B}+K_{B}-\frac{a}{6}, \\
& \frac{d W_{B}}{d\left(L_{1}+L_{2}\right)}=-\frac{a}{6}-\frac{\partial h_{B}}{\partial Q_{B}} \frac{\partial Q_{B}}{\partial\left(L_{1}+L_{2}\right)}, \\
& \frac{d W_{B}}{d L_{A}}-\frac{d W_{B}}{d L_{B}}=\frac{\partial W_{B}}{\partial L_{B}}+\frac{\partial W_{B}}{\partial\left(L_{1}+L_{2}\right)}\left[\frac{d\left(L_{1}+L_{2}\right)}{d L_{A}}-\frac{d\left(L_{1}+L_{2}\right)}{d L_{B}}\right] \\
& \quad=-a L_{B}+K-\frac{a}{6}+\left(-\frac{a}{6}-\frac{\partial h_{B}}{\partial Q_{B}} \frac{\partial Q_{B}}{\partial\left(L_{1}+L_{2}\right)}\right)\left[\frac{d\left(L_{1}+L_{2}\right)}{d L_{A}}-\frac{d\left(L_{1}+L_{2}\right)}{d L_{B}}\right]
\end{aligned}
$$

and as $\frac{\partial Q_{B}}{\partial\left(L_{1}+L_{2}\right)}>0$ because increasing $L_{1}+L_{2}$ implies increasing $L_{2}$ but decreasing $L_{1}$. The sign of (19) is not clear in general, but under the assumption of sufficient small $a$ (rate of marginal change of marginal products), we can assert (19) 
should be positive. Thus in Case 1 (2), Country B gains (loses) from migration between developed countries.

\section{PROPOSITION}

Consider the case that Country $A$ adopts the qualitative restriction policies of sufficiently selective and not so effective, while Country $B$ adopts quantitative restriction policy. If the wage rates of developed countries are different, after economic integration with free labour mobility, both countries will gain in the case of migration from $B$ to $A$, but both countries will lose in the case of migration from $A$ to $B$.

The above proposition suggests that integration of two developed countries may cause both win-win result and lose-lose result if free migration occurs between countries with heterogeneous immigration policies. Moreover wage gap between two develop countries is crucial whether integration ends in win-win or lose-lose.

The intuitive understanding of this result is as follows. In case 1 , total number of immigrants from Country $C$ to Country $A$ increases. Thus Country $A$ gains from economic integration because increased national income dominates the negative effect caused by declined immigrants' quality. On the other hand, in Country $B$, marginal products of labour should increase after the outflow of domestic workers. Thus $B B$ ' line in Figure 2 shifts upward which makes it possible to expand optimal size of area $S$. In case that his positive effect dominates the negative effect of decreasing population (and national income), we can conclude that country $B$ also gains.

\section{Concluding Remark}

In the past decades we have observed a trend of an increasing regional and multilateral harmonization and coordination of economic and social policies related to global interactions (trade agreements, international financial regulation, international investment rules, coordination of fiscal policies). The regulation of international migration flows is a key exception to this trend. In fact, rich countries show little signs of reducing their sovereignty over immigration policy even in areas of strong and pervasive policy integration such as the European Union.

In this paper we consider the case of two rich destination countries which employ heterogeneous immigration policies - qualitative restrictions with minimum skills-entry requirements (and imperfect contrast of illegal migration) vs immigration 
quota - and investigate the effects of free mobility of native workers between the two rich destination countries. We find that labour market integration may lead to win-win or lose-lose situation depending on the wage gap between two countries. The results have important policy implications in particular for countries such as the EU members that have strongly integrated markets and represent alternative destinations for third country nationals.

\section{APPENDIX}

Assume $\frac{\partial Q_{A}}{\partial L_{j}}$ is constant near equilibrium. Totally differentiating (5') and (8) yields the following matrix:

$$
\begin{gathered}
{\left[\begin{array}{rr}
-a\left(1+\frac{\partial L_{2}}{\partial L_{1}}\right)+\left(w_{A}^{M}-\frac{\partial h_{A}}{\partial Q_{A}} \frac{\partial Q_{A}}{\partial L_{2}}\right) \Psi & -a\left(1+\frac{\partial L_{2}}{\partial L_{1}}\right)+\left(w_{A}^{M}-\frac{\partial h_{A}}{\partial Q_{A}} \frac{\partial Q_{A}}{\partial L_{2}}\right) \Phi \\
-\frac{5 a}{3}(1-\rho) & -\frac{5 a}{3}(1-\rho)-\rho^{\prime}\left(w_{A}^{M}-w_{C}^{M}\right)
\end{array}\right]\left[\begin{array}{l}
d L_{1} \\
d L_{2}
\end{array}\right]} \\
=\left[\begin{array}{c}
0 \\
a(1-\rho)
\end{array}\right] d L_{A}+\left[\begin{array}{c}
0 \\
-\frac{a}{3}(1-\rho)
\end{array}\right] d L_{B},
\end{gathered}
$$

where

$$
\Psi=\frac{\partial^{2} L_{2}}{\partial L_{1}^{2}}=\frac{-\frac{5 a}{3}(1-\rho) \rho^{\prime}\left(\frac{\partial w_{A}^{M}}{\partial L_{1}}-\frac{\partial w_{C}^{M}}{\partial L_{1}}\right)}{\left\{\frac{5 a}{3}(1-\rho)+\rho^{\prime}\left(w_{A}^{M}-w_{C}^{M}\right)\right\}^{2}}
$$

and $\Phi=\frac{\partial^{2} L_{2}}{\partial L_{1} \partial L_{2}}=\frac{-\frac{5 a}{3}\left(\rho^{\prime}\right)^{2}\left(w_{A}^{M}-w_{C}^{M}\right)-\frac{5 a}{3}(1-\rho) \rho^{\prime}\left(\frac{\partial w_{A}^{M}}{\partial L_{2}}-\frac{\partial w_{C}^{M}}{\partial L_{2}}\right)}{\left\{\frac{5 a}{3}(1-\rho)+\rho^{\prime}\left(w_{A}^{M}-w_{C}^{M}\right)\right\}^{2}}$. Remembering the assumption that near equilibrium point, $\frac{\partial Q_{A}}{\partial L_{1}}\left(\frac{\partial Q_{A}}{\partial L_{2}}\right)$ is positive (negative) in sign, $\rho^{\prime}$ is positive in sign and sufficiently small, as $\frac{\partial w_{A}^{M}}{\partial L_{1}}=\frac{\partial w_{A}^{M}}{\partial L_{2}}$ and 
$\frac{\partial w_{C}^{M}}{\partial L_{1}}=\frac{\partial w_{C}^{M}}{\partial L_{2}}$, we can conclude that $\Psi>\Phi>0$ and thus the determinant of the matrix of LHS of (A1), $\Delta$, is positive.

$$
\begin{gathered}
\frac{d L_{1}}{d L_{A}}-\frac{d L_{1}}{d L_{B}}=\frac{1}{\Delta}\left|\begin{array}{cc}
0 & -a\left(1+\frac{\partial L_{2}}{\partial L_{1}}\right)+\left(w_{A}^{M}-\frac{\partial h_{A}}{\partial Q_{A}} \frac{\partial Q_{A}}{\partial L_{2}}\right) \Phi \\
\frac{4 a}{3}(1-\rho) & -\frac{5 a}{3}(1-\rho)-\rho^{\prime}\left(w_{A}^{M}-w_{C}^{M}\right)
\end{array}\right| \\
=\frac{1}{\Delta}\left[a\left(1+\frac{\partial L_{2}}{\partial L_{1}}\right)-\left(w_{A}^{M}-\frac{\partial h_{A}}{\partial Q_{A}} \frac{\partial Q_{A}}{\partial L_{2}}\right) \Phi\right] \frac{4 a}{3}(1-\rho)>0, \\
\frac{d L_{2}}{d L_{A}}-\frac{d L_{2}}{d L_{B}}=\frac{1}{\Delta}\left|\begin{array}{cc}
-a\left(1+\frac{\partial L_{2}}{\partial L_{1}}\right)+\left(w_{A}^{M}-\frac{\partial h_{A}}{\partial Q_{A}} \frac{\partial Q_{A}}{\partial L_{2}}\right) \Psi & 0 \\
-\frac{5 a}{3}(1-\rho) & \frac{4 a}{3}(1-\rho)
\end{array}\right| \\
=-\frac{1}{\Delta}\left[a\left(1+\frac{\partial L_{2}}{\partial L_{1}}\right)-\left(w_{A}^{M}-\frac{\partial h_{A}}{\partial Q_{A}} \frac{\partial Q_{A}}{\partial L_{2}}\right) \Psi\right] \frac{4 a}{3}(1-\rho)<0, \\
\frac{d L_{1}+d L_{2}}{d L_{A}}-\frac{d L_{1}+d L_{2}}{d L_{B}}=\frac{1}{\Delta}\left[-\left(w_{A}^{M}-\frac{\partial h_{A}}{\partial Q_{A}} \frac{\partial Q_{A}}{\partial L_{2}}\right)(\Phi-\Psi)\right] \frac{4 a}{3}(1-\rho)>0 .
\end{gathered}
$$




\section{References}

Bertoli, S., H. Brucker, G. Facchini, A.M. Mayda and G. Peri (2009), “The Batte for Brains: How to Attract Talent", Report for the Fondazione Rodolfo De Benedetti, Milano, www.frdb.org.

Bhagwati, J. N. (1973), "International Factor Movements and National Advantage," Indian Economic Review, pp. 73-100.

Bhagwati J. N., and T. N. Sirinivasan (1983), "On the Choice between Capital and Labor Mobility,” Journal of International Economics, Vol. 14, pp. 209-221.

Bruecker H., and P.J.H. Schroder (2010), “Migration Regulation Contagion”, mimeo

Calvo, G., and I. Coelho (1983), “International Factor Mobility and National Advantage,” Journal of International Economics, Vol. 14, pp. 103-114.

Djajic, S. (1989), "Skills and the Pattern of Migration: The role of Qualitative and Quantitative Restrictions on International Labor Mobility”, International Economic Review, Vol. 30, No. 4, pp. 795-809.

Fernandez-Huertas Moraga, J. (2008), “A general model of bilateral migration agreements”, UFAE and IAE working paper n. 755.08

Jones, R. W. and I. Coelho (1985), "International Factor Movements and Ramaswami Argument,” Economica, Vol. 52, pp. -364.

Jones, R. W. and S. T. Easton (1989), "Perspectives on 'Buy-outs' and the Ramaswami Effect,” Journal of International Economics, Vol. 27, pp. 363-371.

Jones, R. W., I. Coelho and S. T. Easton (1986), “The Theory of International Factor Flows; The Basic Model,” Journal of International Economics, Vol. 20, pp. 313-327.

Kondoh, K. (2000), "Legal Migration and Illegal Migration: The Effectiveness of Qualitative and Quantitative Restriction Policies," Journal of International Trade and Economic Development, Vol. 9, No.3, pp. 227-245. 
Kuhn, P. and I. Wooton (1987), "International Factor Movements in the Presence of a Fixed Factor,” Journal of International Economics, Vol. 21, pp. 123-140.

OECD-SOPEMI (2010), International Migration Outlook, SOPEMI

MacDougall, G. D. A. (1960), "The Benefits and Costs of Private Investment from Abroad: A Theoretical Approach", Economic Record, pp. 13-35. Reprinted in John H. Dunning (ed.), International Investment (Penguin Books, 1972), chapter 5, pp. 129-158. Also reprinted in Caves \& Johnson (AEA), chapter 10, pp. 172-194.

Ramaswami, V. K. (1969), "International Factor Movement and the National Advantage,” Economica, Vol. 35, pp. 309-310.

Ruffin, R. (1984), “International Factor Movements,” in R. Jones and P. Kenen, (eds.), Handbook of International Economics, Vol.1 (North-Holland, Amsterdam).

Webb, L. R. (1970), "International Factor Movement and the National Advantage, A Comment,” Economica, Vol. 37, pp. 81-84. 
Figure 1 - The distribution of the labor stock in the developing Country $C$

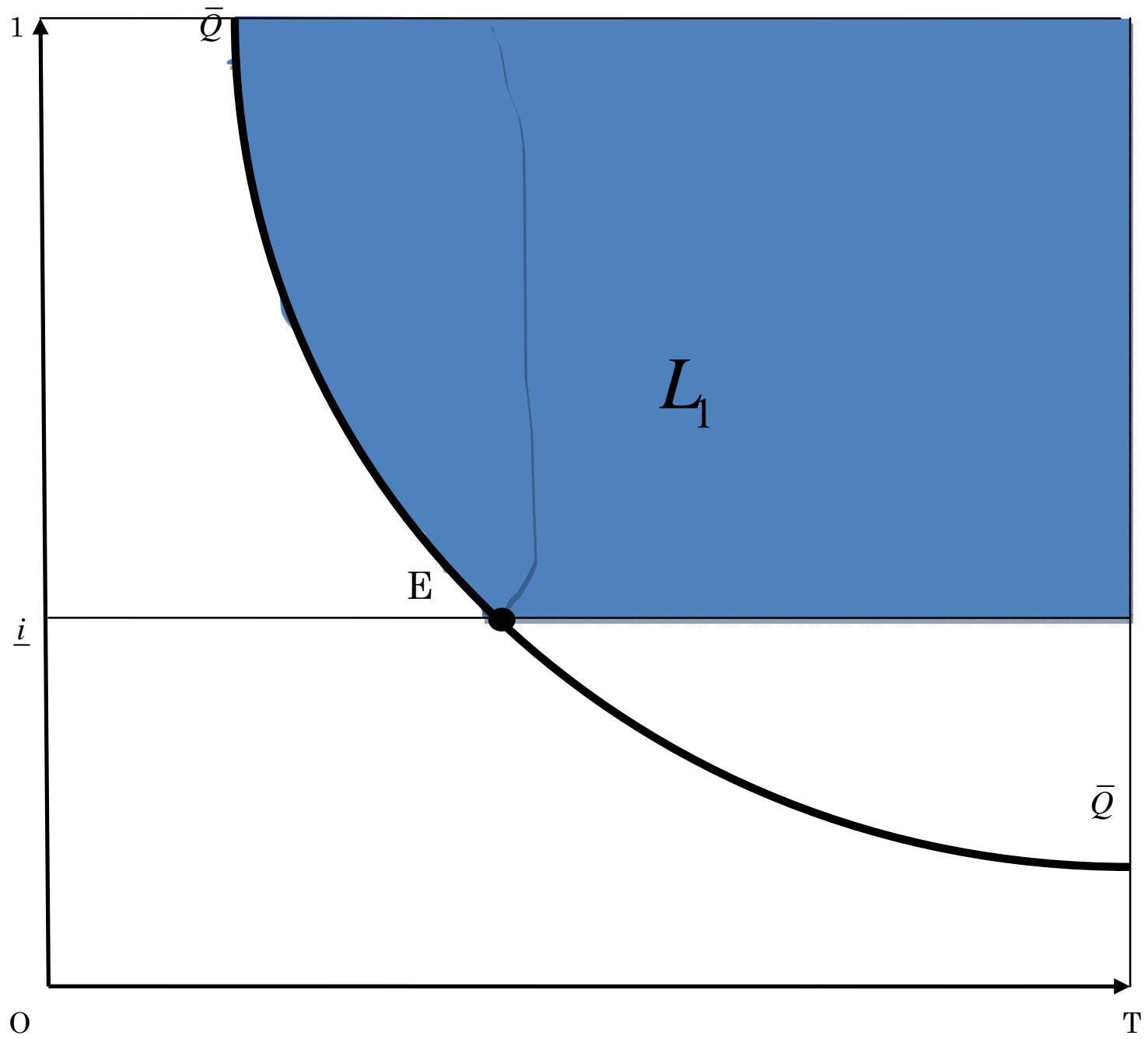


Figure 2 - Immigration Quota in Country B

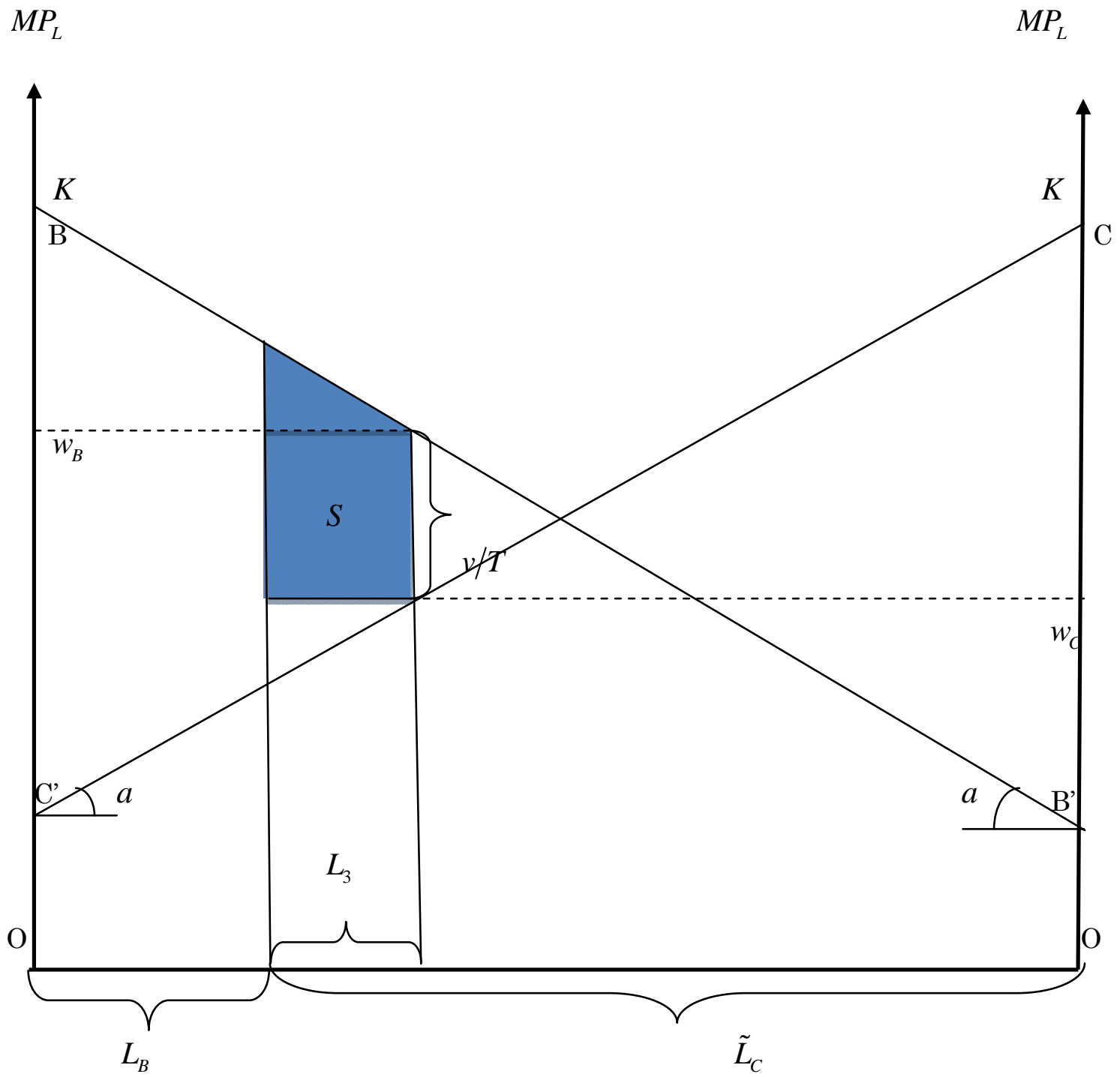

